\title{
EDITORIAL
}

\section{Avoiding confusion in COPD: from risk factors to phenotypes to measures of disease characterisation}

\author{
A. Agustíi*\#, and B. Celli ${ }^{+}$
}

D ecause chronic obstructive pulmonary disease (COPD) is a complex disorder with different pulmonary and extrapulmonary manifestations [1], there is great interest in better understanding the complexity of COPD in order to facilitate a more accurate risk stratification of patients and a better understanding of disease pathobiology, and eventually develop more targeted therapy and improved management of patients with the disease. One end-product of the great number of studies addressing the complexity of COPD has been the emergence of several concepts and terms that are often used (and misused) in scientific discussions and publications (table 1). The purpose of this article is to contribute to the clarification of these concepts by summarising the meaning of the terms, so the scientific community can communicate and discuss advances in the field of COPD, being confident that there is no uncertainty or misunderstanding in their use. We accept this to be only a first proposal and that some investigators may disagree with its content. We invite them to correspond with us in the European Respiratory Journal such that, eventually, a consensus may emerge.

\section{RISK FACTOR}

A risk factor is "an aspect of personal behaviour or lifestyle, environmental exposure, or inborn or inherited characteristic, which, on the basis of epidemiological evidence, is known to be associated with a health-related condition" [2]. Examples of well-established risk factors in COPD include age [9], smoking [10], sex [11], lower socioeconomic and educational level [12], and $\alpha_{1}$-antitrypsin deficiency [13]. Some of the risk factors are modifiable and, therefore, are to be "prevented", while others influence the expression of the disease but are not modifiable, such as age or sex. From this definition, it is evident that a risk factor, therefore, is not a phenotype.

\section{PHENOTYPE}

Generally speaking, a phenotype is any "observable structural and functional characteristics of an organism determined by its genotype and modulated by its environment" [3]. Having brown or blue eyes, for example, is a phenotype. Yet, a recent consensus definition [4] highlighted that, in order to be clinically useful, a "clinical" phenotype must be related to

\footnotetext{
*Thorax Institute, Hospital Clinic and IDIBAPS, "Universidad Barcelona, Barcelona, and "Fundación Cimera, CIBER Enfermedades Respiratorias (CIBERES), Mallorca, Spain. ${ }^{+}$Pulmonary and Critical Care Division, Brigham and Women's Hospital, Harvard University, Boston, MA, USA.

CORRESPONDENCE: A. Agustí, Thorax Institute, Hospital Clínic, Villarroel 170, Escala 3, Planta 5 08036 Barcelona, Spain. E-mail: alvar.agusti@clinic.ub.es
}

clinically meaningful outcomes, such as symptoms, response to therapy, rate of disease progression or death [14]. So far, brown and blue eyes are not known to be related to any of those. By contrast, having upper lobe emphysema and poor exercise capacity is known to be associated with a significantly better outcome after lung volume reduction surgery compared with standard medical therapy [15]. Thus, this combination of disease attributes that requires a specific form of therapy to change an important outcome (mortality) fulfils perfectly the definition of a clinical phenotype [4]. The frequent exacerbator is another recently described clinical phenotype [16]. Other phenotypes that are associated with poor outcomes in COPD are patients with low body mass index (BMI) [17], increased functional dyspnoea [18] and poor exercise capacity [19]. These phenotypes may respond to therapies such as pulmonary rehabilitation and appropriate nutrition, and are therefore important to identify. The clinical relevance of other proposed phenotypes requires prospective validation [20]. Finally, some risk factors (e.g. $\alpha_{1}$-antitrypsin deficiency) may also be considered, in some cases, as phenotypes, since they may require specific therapeutic measures.

A different concept that is often used, and we predict will be increasingly used in the future, is that of "intermediate phenotypes" or "endotypes" [5, 6], which correspond to the genome or proteome responses that form the basis of the human biological armamentarium to respond to injury (thrombosis, inflammation, immune response, fibrosis and apoptosis/necrosis) [6]. Eventually, it is the intensity and combination of these intermediate phenotypes that lead to the clinical and pathological manifestations of diseases [6].

\section{DISEASE CHARACTERISATION: SEVERITY, ACTIVITY AND TIMING}

Finally, three disease-related concepts need discussion. The severity of any disease (including COPD) relates to the "extent of functional impairment of the target organ(s)" [7]. In the case of COPD, severity has traditionally been determined by the degree of airflow limitation (assessed by measuring forced expiratory volume in $1 \mathrm{~s}(\mathrm{FEV} 1))$ [21], although in recent years, several composite measures, such as the BODE (BMI, airflow obstruction, dyspnoea and exercise capacity) [22] and ADO (age, dyspnoea and obstruction) [9] indices, among others, have been shown to prognosticate survival more accurately in these patients. Importantly, FEV1, BODE and ADO are not risk factors and are not phenotypes, although they may include components of both; they are measurements of disease severity 


\begin{tabular}{|c|c|c|}
\hline Term & Definition & [Ref.] \\
\hline Clinical phenotype & $\begin{array}{c}\text { A single disease attribute or combination of disease attributes that describes } \\
\text { differences between individuals with COPD as they relate to clinically } \\
\text { meaningful outcomes }\end{array}$ & [4] \\
\hline $\begin{array}{l}\text { Intermediate patho-phenotype or } \\
\text { endo-phenotype }\end{array}$ & $\begin{array}{l}\text { Types of human biological responses to injury (thrombosis, inflammation, } \\
\text { immune response, fibrosis and apoptosis/necrosis) }\end{array}$ & {$[5,6]$} \\
\hline Disease severity & Extent of functional loss of the target organ(s) & {$[7]$} \\
\hline
\end{tabular}

that are useful to establish prognosis (prognostic factors) and guide therapy.

However, the activity of a disease is a concept that relates to the "level of activation of the biological processes that drive disease progression" [7, 8]. This is a well-established concept in other diseases (e.g. rheumatoid arthritis and tuberculosis) but, to date, is not well defined in COPD [7]. Clearly, this is a gap that requires novel research [8]. It is probable that identification and therapy that addresses disease activity will differ from maintenance therapy for stable and inactive disease, independent of its severity.

Finally, the concept of the temporal presentation of disease (early versus late disease) refers to the time-point during the natural history of a disease at which it is diagnosed or studied. These terms are often misused synonymously with severity of disease (mild and severe, respectively). A 75-yr-old COPD patient with an FEV1 of $70 \%$ predicted has mild disease but, most likely, not early disease. Conversely, a 45-yr-old COPD patient with an FEV1 of 50\% predicted certainly has severe disease and, temporally, it is likely to represent early disease [23]. So, severity refers to the loss of function whereas early refers to a timescale, and both may coincide or not. This consideration is important since several recent post hoc analyses of large, randomised clinical trials suggest that patients with Global Initiative for Chronic Obstructive Lung Disease (GOLD) stage II COPD can have a faster rate of FEV1 decline than those with GOLD stage III-IV disease [24, 25]. These otherwise very interesting and challenging observations are often misinterpreted as relating to early disease when, strictly speaking, they relate to disease severity.

We hope that this proposal will help stimulate critical thinking on these issues and, in particular, help reach an agreement on concepts and terminology, with the long-term goal of facilitating a better understanding of the complexity of COPD [7] and, eventually, a better treatment of these patients.

\section{STATEMENT OF INTEREST}

None declared.

\section{ACKNOWLEDGEMENTS}

This article was inspired by the discussion held during the XVI International Pneumology Symposium organised in Seville (Spain) on February 4-5, 2011. The authors thank all delegates for their participation in the debate and the organiser (J. Castillo; Fundacion Coll-Colome, Seville, Spain) for creating the adequate environment for such a debate to emerge.

\section{REFERENCES}

1 Agusti A, Calverley P, Celli B, et al. Characterisation of COPD heterogeneity in the ECLIPSE cohort. Respir Res 2010; 11: 122-136.

2 National Center for Biotechnology Information. MeSH: Risk Factors. www.ncbi.nlm.nih.gov/mesh/68012307 Date last updated: 1988.

3 Rice JP, Sacccone NL. Definition of the phenotype. Adv Genet 2001; 42: 69-76.

4 Han MK, Agusti A, Calverley PM, et al. Chronic obstructive pulmonary disease phenotypes: the future of COPD. Am J Respir Crit Care Med 2010; 182: 598-604.

5 Freimer N, Sabatti C. The human phenome project. Nat Genet 2003; 34: 15-21.

6 Loscalzo J, Kohane I, Barabasi AL. Human disease classification in the postgenomic era: a complex systems approach to human pathobiology. Mol Syst Biol 2007; 3: 124.

7 Agusti A, Sobradillo P, Celli B. Addressing the complexity of COPD: from phenotypes and biomarkers to scale-free networks, systems biology and P4 medicine. Am J Respir Crit Care Med 2011; 183: 1129-1137.

8 Vestbo J, Rennard S. Chronic obstructive pulmonary disease biomarker(s) for disease activity needed - urgently. Am J Respir Crit Care Med 2010; 182: 863-864.

9 Puhan MA, Garcia-Aymerich J, Frey M, et al. Expansion of the prognostic assessment of patients with chronic obstructive pulmonary disease: the updated BODE index and the ADO index. Lancet 2009; 374: 704-711.

10 Kohansal R, Martinez-Camblor P, Agusti A, et al. The natural history of chronic airflow obstruction revisited: an analysis of the 
Framingham Offspring Cohort. Am J Respir Crit Care Med 2009; 180: 3-10.

11 De Torres JP, Cote CG, Lopez MV, et al. Sex differences in mortality in patients with COPD. Eur Respir J 2009; 33: 528-535.

12 Menezes AM, Perez-Padilla R, Jardim JR, et al. Chronic obstructive pulmonary disease in five Latin American cities (the PLATINO study): a prevalence study. Lancet 2005; 366: 1875-1881.

13 Stockley RA. Alpha-1-antitrypsin deficiency: what next? Thorax 2000; 55: 614-618.

14 Jones PW, Agusti AGN. Outcomes and markers in the assessment of chronic obstructive pulmonary disease. Eur Respir J 2006; 27: 822-832.

15 National Emphysema Treatment Trial Research Group. A randomized trial comparing lung-volume-reduction surgery with medical therapy for severe emphysema. N Engl J Med 2003; 348: 2059-2073.

16 Hurst JR, Vestbo J, Anzueto A, et al. Susceptibility to exacerbation in chronic obstructive pulmonary disease. N Engl J Med 2010; 363: $1128-1138$.

17 Schols AM, Broekhuizen R, Weling-Scheepers CA, et al. Body composition and mortality in chronic obstructive pulmonary disease. Am J Clin Nutr 2005; 82: 53-59.

18 Nishimura K, Izumi T, Tsukino M, et al. Dyspnea is a better predictor of 5-year survival than airway obstruction in patients with COPD. Chest 2002; 121: 1434-1440.
19 Cote CG, Casanova C, Marin JM, et al. Validation and comparison of reference equations for the 6-min walk distance test. Eur Respir J 2008; 31: 571-578.

20 Burgel PR, Paillasseur JL, Caillaud D, et al. Clinical COPD phenotypes: a novel approach using principal component and cluster analyses. Eur Respir J 2010; 36: 531-539.

21 Rabe KF, Hurd S, Anzueto A, et al. Global strategy for the diagnosis, management, and prevention of chronic obstructive pulmonary disease: GOLD executive summary. Am J Respir Crit Care Med 2007; 176: 532-555.

22 Celli BR, Cote CG, Marin JM, et al. The body-mass index, airflow obstruction, dyspnea, and exercise capacity index in chronic obstructive pulmonary disease. N Engl J Med 2004; 350: 1005-1012.

23 Morice AH, Celli B, Kesten S, et al. COPD in young patients: a prespecified analysis of the four-year trial of tiotropium (UPLIFT). Respir Med 2010; 104: 1659-1667.

24 Jenkins CR, Jones PW, Calverley PM, et al. Efficacy of salmeterol/ fluticasone propionate by GOLD stage of chronic obstructive pulmonary disease: analysis from the randomised, placebocontrolled TORCH study. Respir Res 2009; 10: 59.

25 Decramer M, Celli B, Kesten S, et al. Effect of tiotropium on outcomes in patients with moderate chronic obstructive pulmonary disease (UPLIFT): a prespecified subgroup analysis of a randomised controlled trial. Lancet 2009; 374: 1171-1178. 